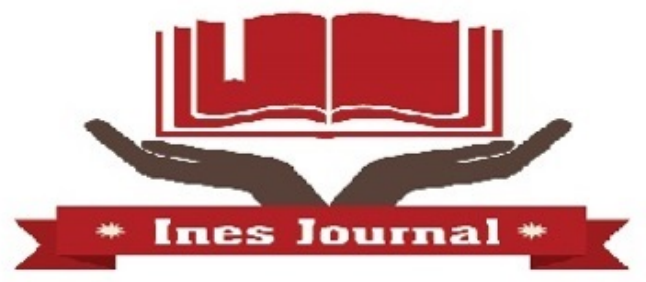

\title{
INESJOURNAL
}

ULUSLARARASI EĞİTIM BİLİMLERİ DERGİSİ THE JOURNAL OF INTERNATIONAL EDUCATION SCIENCE

Yıl: 2, Sayı: 5, Aralık 2015, s. 89-97

\author{
Yeliz KAYA $^{1}$, Rafet GÜNAY ${ }^{2}$, Fadime Koç DAMGACI ${ }^{3}$
}

\section{KİRKPATRİCK DÖRT DÜZEY PROGRAM DEĞERLENDİRME MODELI}

Özet

Zengin bir içeriğe sahip olan Kirkpatrick değerlendirme modeli, verilen eğitimle ilgili sonuçların davranışsal olarak da ortaya çıkıp çıkmadığını ortaya koymaya çalışan önemli bir modeldir. Model, tepki, öğrenme, davranış ve sonuç bölümlerinden oluşmaktadır. Organizasyonel değişim ve düzenlemeler için başka farklı değerlendirme modelleri de olmasına rağmen Kirkpatrick Dört Düzey Değerlendirme Modeli oldukça önemli bir popülariteye sahiptir. Kirkpatrick, bu popülaritenin modelin pratik ve basit olmasından kaynaklandığını ifade etmektedir. Daha çok iş eğitimlerinin değerlendirilmesinde kullanılmakla birlikte son zamanlarda yükseköğretim programlarının değerlendirilmesinde de kullanılmaktadır. Türkçe alanyazın incelendiğinde Kirkpatrick değerlendirme modeliyle yapılan az sayıda çalışma olduğu görülmektedir. Bu çalışmanın amacı Kirkpatrick Dört Düzey Değerlendirme Modelinin ne olduğu ve nasıl uygulandığını ayrıntılı olarak ele alarak bu konudaki alanyazına katkıda bulunmaktır.

Anahtar Kelimeler: Dört Düzey Program Değerlendirme, Kirkpatrick Değerlendirme Modeli, Program Değerlendirme.

\section{KIRKPATRICK'S FOUR-LEVEL EVALUATION MODEL}

\begin{abstract}
Kirkpatrick program evaluation model with its rich content is quite useful for evaluating whether the education given has also behavioral outcomes. It consists of reaction, learning, behavior and outcomes. Although there are other models for evaluating organizational change and regulations, Kirkpatrick's Four-Level Evaluation Model is very popular because of its practicality and simplicity. While it is usually used for the evaluation of vocational education, it is increasingly being used for the evaluation of higher education programs. Regardless of its importance, very few studies exist on the subject in Turkish educational research literature. Therefore, the purpose of this study is to introduce Kirkpatrick's Four-Level Evaluation Model and provide a detailed account of its implications in the educational research.
\end{abstract}

1 Doktora Öğrencisi, Yıldız Teknik Üniversitesi Eğitim Programları ve Öğretimi, yelizkizmazer@gmail.com

2 Doktora Öğrencisi, Yıldız Teknik Üniversitesi Eğitim Programları ve Öğretimi, gunay.rafet@gmail.com

3 Doktora Ögrencisi, Yıldız Teknik Üniversitesi Eğitim Programları ve Öğretimi, fdamgaci@gmail.com 
Keywords: Four-Level Program Evaluation, Kirkpatrick Evaluation Model, Program Evaluation.

\section{GíRiş}

Değerlendirme kelimesi çoğunlukla öğrencileri belgeleme ve derecelendirme olarak kullanılmıştır. Aynı zamanda onay belgesi amaçlarına göre değerlendirme, öğrencinin katıldığ program veya kurumsal öğrenme amaçlarından hangilerini edindiğini belirlemeye yönelik veri toplama olarak da adlandırılır. Bundan dolayı değerlendirme ders, sınıf, program, genel eğitim ve kurum gibi pek çok boyutta bulunur. Değerlendirme hakkında bazı araştırmacılar; değerlendirmenin öğrencinin öğrenmesini gözlemleyen ve arttıran devam eden bir süreç olduğunu, bazıları öğrencilerin akademik hayatlarının değişik aşamalarında ne bildiklerini ve ne yapabileceklerini belirlemeye yönelik geçerli ve doğru bilgi edinmeyi sağlayacak metotları içerdiğini ifade eder. Son zamanlarda değerlendirmede öğrenci öğrenmesiyle alakalı olarak eğitim programının kalitesi de önemli ölçüde dikkate alınır olmuştur (Praslova, 2010). Program değerlendirmede çeşitli modellerden faydalanılmaktadır. Organizasyonel düzeyde verilen eğitim programlarının değerlendirilmesinde Kirkpatrick değerlendirme modeli yaygın olarak kullanılmaktadır.

\section{KİRKPATRİCK DÖRT DÜZEY DEĞERLENDİRME MODELİ}

Kirkpatrick, dört düzey değerlendirme modelini 1954 yılında doktora tezi kapsamında geliştirmiştir. Kirkpatrik'in, dört düzey modelini geliştirirken üzerinde çalıştığ orijinal çalışması yönetimsel bir eğitim programını değerlendirme üzerinedir (Kirkpatrick, J. 2007). Kirkpatrik dört düzey modeli, bir değerlendirme mozaiğinin parçaları olarak çeşitli gösterge ve enstrümanların rolünü anlamak için zengin içerik sağlar. Dört düzey modeli ayrıca kurumlara çok daha özel ve ayırt edici olacak eğitim programlarının etkililiğini gözden geçirmeleri için bir geri dönüt sağlar. Bu model organizasyonel değişim ve düzenlemeler için oldukça uygundur (Praslova, 2010).

Uzun süreden beri eğitim programları için önerilen benzer dört adım eğitim programı değerlendirme yaklaşımları olmasına rağmen, Kirkpatrick'in modeli en çok bilinenidir (Kaufman \& Keller,1994; Praslova, 2010). Dört düzey modeli çok geniş kitlelere ulaşmış ve devam eden bir popülariteye sahiptir (Alliger \& Janak, 1989). Kirkpatrick, bu modelin günümüzde hala popüler olarak kullanılmasının formülünün çok basit olduğunu, bu durumun modelin pratik ve basit olmasından kaynaklandığını ifade etmektedir (Hayes, 2008). Ayrıca bu model gücünü, değerlendirme konusunda kabataslak bir sinıflama yaparak eğitimin değerlendirilmesini kolaylaştırmasından alır (Alliger \& Janak, 1989).

Kirkpatrik'in dört düzey değerlendirme modeli organizasyonal performans, müşteri memnuniyeti ve toplumsal katkılarla ilgili tüm çabaları destekler ve bunlarla uyumludur (Kaufman \& Keller,1994). Bunun yanı sıra son yıllarda yüksek öğretimde programların değerlendirilmesinde de kullanılmaya başlanılmıştır (Praslova, 2010).

Kirkpatrick bir değerlendirme yapmayı gerektirecek nedenleri şu şekilde sıralamıştır; programın devam edip etmeyeceğine karar vermek, programı geliştirmek, öğrenme uygunluğunu sağlamak (Kirkpatrick, D. \& Kirkpatrick, J., 2006), eğitimin değerini maksime etmek, eğitimi stratejiyle sıraya koymak ve eğitimin değerini göstermek (Kirkpatrick, J. 2007). 


\section{Kirkpatrick Dört Düzey Program Değerlendirme Modeli}

Değerlendirme planlanarak ve amaçları belirlenerek yapılmalıdır. Amaçlarına karar verdikten sonra hangi tekniğin ve araçların kullanılacağına karar verilmelidir. Değerlendirmenin planlanması, sınırlı kaynakların etkili kullanımına olanak sağlayacak ve insanların gereğinden fazla sorgulanmasının önüne geçecektir (Kirkpatrick, J. 2007).

Eğitim programlarının değerlendirilmesi sadece eğitim öncesi ve sonrası durumun değerlendirildiği bir form kâğıdının doldurulması değildir. Değerlendirme aynı zamanda eğitim programının daha da iyi hale getirilmesine fırsat sunar ve görev için kritik olan davranışların gösterilmesine büyük katkıda bulunur. Eğitim veren yöneticilerin değerlendirmeyi eğitim öncesi ve sonrası verilen değerlendirme kâğıdı olarak görmeleri, değerlendirme için kullanılacak kaynakların isteksizce kullanılmasına neden olur (Kirkpatrick, D. \& Kirkpatrick, J. 2007).

Yapılacak değerlendirmede verilen eğitim programının kimlere verildiği ve onların değerlendirme sürecine ne kadar yardımda bulunacağ gerekir. Değerlendirmeye dışarıdan katkı sağlayabilecek danışmanlar da bütçe dâhilinde gözden geçirilmeli ve uygun ölçüde dışarıdan tayin edilecek bir danışmana gereksinim olup olmadığına karar verilmelidir. Tüm bunlar hesap edilerek değerlendirmeye ne kadar zaman ve çaba sarf edileceği belirlenmelidir. Eğitim kısmının sınırlı kaynakları, menajerlerin sorgulanabilir yardımları ve dışarıdan bir danışman tayin etme konusunda sınırlı bütçe göz önüne alınarak mümkün olan en iyi değerlendirme sonuçlarına ulaşılmaya çalışılmalıdır (Kirkpatrick ,D. \& Kirkpatrick, J. 2007). Kirkpatrick, D. (2006), dört düzey modelinin uygulanmasındaki yedi anahtar noktayı şu şekilde ifade eder;

1. Anahtar: Kaynaklarını analiz et.

2. Anahtar: İdarecilerle iyi ilişsiler geliştir.

3. Anahtar: Birinci düzeyden başla ve kaynaklar izin verdiği ölçüde ikinci, üçüncü ve dördüncü düzeylere ilerle.

4. Anahtar: Tepkiyi değerlendir.

5. Anahtar: Öğrenmeyi değerlendir.

6. Anahtar: Davranışı değerlendir.

7. Anahtar: Sonuçları değerlendir

Kirkpatrick modelindeki her bir düzey bir öncekinden daha bilgilendiricidir. Tüm düzeyler sebep sonuç ilişkisi açısından birbiriyle bağlantılıdır ve tüm düzeyler birbiriyle olumlu yönde ilişkilidir (Alliger \& Janak, 1989).

Kirkpatrick değerlendirme modelinde tepki, öğrenme, davranış ve sonuç olmak üzere dört düzey vardır (Rajeev, Madan \& Jayarajan, 2009; Kirkpatrick, D. \& Kirkpatrick, J. 2007; Kaufman \& Keller,1994; Kirkpatrick,D., 1996). Bu dört alan, değerlendirilmesi oldukça önemli olan alanlardır. Fakat 3. ve 4. düzeyin değerlendirilmesi ilk iki basamağa göre zor olabilmektedir. 3. ve 4. düzeyin önemi ve niteliği ile ilgili literatürde oldukça fazla bilgi olmasına rağmen, uygulamada kullanım sıklığı daha azdır (Kaufman \& Keller,1994).

Birinci düzey, program hakkındaki "hoşlanmalar" ve "duygular"1 içerir. Davranışlardan ziyade tutumları kapsar. İkinci aşama olan öğrenme aşaması eğitimi alanların anlamaları ve edinmeleri gereken "gerçekler, prensipler ve teknikler"i kapsar. Üçüncü düzey olan davranış, öğrenilenlerin kullanılmasını kapsar. Dördüncü düzey olan sonuç aşaması ise amaçları ve ulaşılmak istenen

INESJOURNAL

Uluslararası Eğitim Bilimleri Dergisi / The Journal of International Education Science Yll: 2, Sayı: 5, Aralık 2015, s. 89-97 
sonuçları, maliyetin düşürülmesini, devamsızlığın düşürülmesini, şikâyetlerin azaltılmasını, ürünün nitelik ve niceliğindeki artışı, moral artışını kapsar (Alliger \& Janak, 1989)

Düzey 1; Tepki (Reaction): Bu düzey, katılımcıların program hakkındaki tepkilerinin ölçüldüğü aşamadır (Uşun, 2012). Katılımcıların programı ne kadar beğendikleri, program hakkında ne hissettikleri, duyguları bu düzeyde ölçülür (Eroğlu, 2006). Program içeriği, eğitim etkinlikleri, yöntemleri, öğrenme ortamı, eğiticilerin performansı gibi tüm bileşenlerin değerlendirilmesi önemlidir (Özaydın, Günbatar, Önal \& Çakır, 2012). Tepkiler genellikle tutum ölçekleriyle ve program sonrasında ölçülür (Rajeev, Madan \& Jayarajan, 2009). Bunun yanında veri toplamak amacıyla likert tipi anketler, odak grup görüşmeleri ve tepki formları da kullanılabilir (Eroğlu, 2006).

Eğitimin etkili olması için katılımcıların eğitimi beğenmeleri gerekir. Katılımcıların eğitimi beğenmeleri öğrenmeye motive olmaları açısından önemlidir. Bu aşamanın değerlendirilmesi önemlidir çünkü yapılan değerlendirme sonuçları, programın ve öğrenmenin ne kadar etkili olduğu ve programın nasıl geliştirilebileceği hakkında fikir verir (Kirkpatrick; D., 1996). Ayrıca katılımcıların, eğitmenlerin işlerini daha iyi yapabilmek için onların geri bildirimlerine ihtiyaçları olduğunu anlamalarını sağlar. Katılımcılara eğitim hakkındaki fikirleri sorularak onlar da eğitim programına dahil edilir ve programın daha istenen, arzu edilen şekilde olması sağlanarak program, ihtiyaçlara daha iyi cevap verebilecek bir hale getirilebilir (Kirkpatrick, $D$. \& Kirkpatrick, J., 2006). Bu aşamada elde edilen değerlendirme kullanılan form kâğıtları yöneticiler ve eğitimi talep edenler için eğitimin etkililiği hakkında fikir verecek nicel bir veri olarak kullanılabilir. Ayrıca form kâğıtları eğitmenler için daha sonraki eğitimlerin standartlarını oluşturmada nicel veri olarak kullanılabilir.

$\mathrm{Bu}$ aşamanın değerlendirmesi önemli olduğu kadar uygulanması da kolay ve etkilidir (Kirkpatrick; D., 1996). Eğitimin hemen sonrasında uygulanması ve katılımcıların ulaşılabilir durumda olmasının bunda etkisi büyüktür (Özaydın, Günbatar, Önal \& Çakır, 2012). Eğitmenlerin bu aşamayı ölçmek için kullandığı araçların başında tepki formları gelir. Bu tepki formlarından en fazla yarar sağlanabilmesi için şunlara dikkat etmek gerekir (Kirkpatrick; D., 1996);

1. Neyi bilmek istediğine karar verme.

2. Tepkileri ölçebilecek bir form oluşturma.

3. Yorum ve öneri yazmaları için katılımcıları teşvik etme.

4. Tüm sorulara cevap verildiğinden emin olma.

5. Sorulara samimiyetle cevap verilmesini sağlama.

6. Standartlara karşı tepkileri ölçme ve uygun şekilde davranma.

7. Tepkilerle uygun şekilde iletişim kurmaya çalışma.

Düzey 2; Öğrenme (Learning): Bu aşamada öğrenme hedeflerine ulaşılıp ulaşılmadığı tespit edilmeye çalışılır (Rajeev, Madan \& Jayarajan, 2009). Değerlendirmenin eğitimlerin bitiminden hemen sonra veya kısa bir süre sonra yapılması önerilir (Altıntaş, L. \& Alimoğlu, M. K. (2013).

$\mathrm{Bu}$ düzeyde değerlendirme yapılırken genelde "Hangi bilgiler öğrenilmiştir?", "Hangi becerilerin gelişmesi sağlanmıştır?" ve "Hangi tutumlar değişmiştir?" sorularına cevap aranır (Eroğlu, 2006). 


\section{Kirkpatrick Dört Düzey Program Değerlendirme Modeli}

Ölçümler genellikle uygun bir test veya sınavla yapılır (Rajeev, Madan \& Jayarajan, 2009). Bununla birlikte yazılı testler, performans testleri ve anket gibi araçlar da kullanılmaktadır (Eroğlu, 2006). Eğitim boyunca ne öğrenildiğinin tam olarak tespit edilebilmesi için öntest ve sontest yapılması tercih edilir (Rajeev, Madan \& Jayarajan, 2009).

Bir eğitim programında bilgi, beceri ve tutum olmak üzere üç şey öğretilebilir. Bunlardan en az bir veya daha fazlası öğrenilmeden davranış değişikliğinin meydana gelmesi pek mümkün değildir (Kirkpatrick; D., 1996).

Öğrenme aşamasının değerlendirilmesi tepki aşamasına göre daha zor ve zaman alıcıdır. Bu aşamanın değerlendirilmesinde aşağıdaki öneriler faydalı olacaktır (Kirkpatrick, D. \& Kirkpatrick, J., 2006);

1. Elverişli olacaksa bir kontrol grubu kullan.

2. Program öncesi ve sonrasında bilgi, beceri ve tutumu ölçecek değerlendirme araçları kullan.

3. Bilgi ve tutum ölçmek için test kullan.

4. Becerileri ölçmek için performans testi kullan.

5. Tüm sorulardan tam cevaplar al.

6. Değerlendirme sonuçlarına uygun düzenlemeler yap.

Düzey 3. Davranış (Behavior): Bu aşamada amaç, eğitimin iş performansını değiştirip değiştirmediğini öğrenmektir. $\mathrm{Bu}$ aşama, katılımcıların sınıfta öğrendikleri becerileri işte uygulamalarını içerir. Dolayısıyla katılımcıların becerilerinin sınıf ortamında değil iş ortamında araştırılmasını gerektirir. Sonuçlarının doğruluğu açısından değerlendirmenin eğitim programının hemen sonrasında yapılmaması, davranış değişikliğinin gelişmesi için bir süre beklenmesi önerilir (Altıntaş, L. \& Alimoğlu, M. K. 2013). Bu nedenle ölçümlerin yapılabilmesi için eğitim verildikten sonra en az üç hafta geçmesini beklemek gerekir (Eroğlu, 2006).

Bu düzey, testler yoluyla veya gözlem ve yargılar yoluyla değerlendirebilir (Rajeev, Madan \& Jayarajan, 2009). Ayrıca görüşme, soru formları, anket, odak grup çalışması, katılımcılara ödev verilmesi, hareket planları, kontrol listeleri, performans sözleşmeleri ve performans değerlendirme formları da davranış değişikliklerini tespit etmede kullanılabilecek araçlardandır (Eroğlu, 2006).

Üçüncü düzey, değerlendirmelerde en çok unutulan düzey olmasına rağmen eğitimin etkilerini en çok arttıran düzeydir (Kirkpatrick, J. 2007).

Davranış değişiminin tespit edilmesi aşamasında kullanılabilecek genel yöntemler şunlardır; ilk olarak katılımcıların öğretim sonrasında içerik olarak benzer olan başka bir performansı gerçekleştirmeleri istenerek değerlendirme yapılabilir. Katılımcıların eğitim öncesi ve sonrası performansları katılımcılarla benzer özelliklere sahip olan kişilerin performanslarıyla karşılaştırılabilir. Burada eğitimcilerin değerlendirmeleri yanında öğrencilerin kendi değerlendirmelerine, akranlarının yaptığ değerlendirmelere de yer vermekte fayda vardır. Bu ölçümlerin kıyasını yapmak için istatistiksel analizler kullanılmalıdır. Öğretime tabi olmayan kontrol grubunun kıyaslama için kullanılması da ayrıca bu aşamada önerilen bir durumdur (Özaydın, Günbatar, Önal \& Çakır, 2012). 
$\mathrm{Bu}$ aşamada cevap verilecek sorular diğer iki düzeydekine oranla daha karmaşık ve zordur (Kirkpatrick; D., 1996). Çünkü öncelikle katılımcıların davranış değişikliği gösterebilmeleri için önlerine fırsat çıkması gerekir. İkinci olarak davranış değişikliğinin ne zaman meydana geleceğini bilmek imkânsızdır. Katılımcı, önüne çıkan ilk firsatı değerlendirmede sıkıntı yaşayabilir. Bazen istenen davranış, fırsatın hemen sonrasında gösterilir. Bazen de asla gösterilemez. Üçüncü olarak katılımcı davranış değişikliği gösterebilir ve sonrasında “öğrendiğim şeyler iyiydi ve öğrendiğim şekilde davranmaya çalışacağım” veya "öğrendiğim şeyleri beğenmedim, eskisi gibi davranmaya devam edeceğim." diyebilir veya "öğrendiğim şeyler iyiydi fakat patronum yüzünden ve zaman kısıtlaması nedeniyle bu davranışları göstermem mümkün değil." şeklinde bir sonuca varabilir (Kirkpatrick, D. \& Kirkpatrick, J., 2006).

Davranış değişikliği nedeniyle verilen ödüller katılımcının ilk şekilde düşünmesine yardımcı olabilir. Katılımcılara eğitim sonrası işe döndüklerinde bu konuda yardımcı olmak, cesaretlendirmek ve ödüllendirmek oldukça önemlidir ve davranış değişikliğinin meydana gelme olasılığını arttıracaktır. Ödül çeşitlerinden birisi içseldir. Davranış değişikliği meydana geldiğinde katılımcı memnuniyet, gurur, başarı veya mutluluk duygularından birini yaşayabilir ve bu davranış değişikliğinin devam etmesi için içsel bir ödüldür. Dışsal ödüller de bu süreçte önemlidir. Övgü, özgürlük artışı, yetki, maaş artışı gibi ödüller de davranış değişikliğinin devam etmesini sağlayacak dışsal ödüllerdir (Kirkpatrick, D. \& Kirkpatrick, J., 2006).

Davranış değişikliğini ölçme aşamasında davranış değişikliğinin ne zaman ölçüleceği, hangi sıklıkla ve nasıl ölçüleceği soruları önemlidir. Bu düzey değerlendirmeyi yapmada yol gösterecek bazı öneriler şunlardır (Kirkpatrick; D., 1996);

1. Elverişli olacaksa bir kontrol grubu kullan.

2. Davranış değişikliği meydana gelmesi için yeterince zamanın geçmesini bekle.

3. Elverişli olacaksa eğitim öncesi ve sonrası davranış değişikliğini değerlendir.

4. Katılımcı, katılımcıların en yakındaki şefi, katılımcıların altında çalışanlar ve katılımcıların davranışlarını sıklıkla gözlemleyebilen diğer kişilerden biri veya daha fazlası ile görüşme veya anket yap.

5. Soruların tamamına cevap al.

6. Değerlendirmeyi uygun zamanlarda tekrarla.

7. Yarar maliyet dengesini koru.

Düzey 4; Sonuçlar (Results): Bu aşama, programın maliyeti ve yararları, maliyeti düşürmenin kuruma etkisi, işteki niteliksel ve niceliksel artış (Rajeev, Madan \& Jayarajan, 2009), işgücü değişim oranı, iş kazaları oranı, hata oranları, satışlar, müşteri tatminini ve çalışan tatminini yükseltmek gibi konular hakkında değerlendirmenin yapıldığı bir aşamadır (Eroğlu, 2006).

$\mathrm{Bu}$ aşamanın değerlendirilmesi diğerlerine nazaran daha maliyetli, zaman alıcı ve zordur (Kirkpatrick, D. \& Kirkpatrick, J., 2006; Rajeev, Madan \& Jayarajan, 2009; Eroğlu, 2006). Kurumsal sonuçları etkileyen çok sayıda faktör vardır ve bu faktörlerin etkilerinin ayrıştırılması oldukça güçtür (Eroğlu, 2006). Fakat bu aşamanın tam olarak değerlendirilmesinin kuruma olan katkısının anlaşılması tüm bu sıkıntıları unutturabilir (Rajeev, Madan \& Jayarajan, 2009).

$\mathrm{Bu}$ aşamada eğitimciler şuna benzer soruların cevabını ararlar: Bu eğitim, niteliği ne kadar arttırdı? Bu, kazanca ne kadar yansıdı? Yürütülen program verimliliği ne kadar arttırdı? 


\section{Kirkpatrick Dört Düzey Program Değerlendirme Modeli}

Yöneticilere yeni işçileri eğitmeleri için verdiğimiz oryantasyon sonucunda iş yükümüzde ne oranda bir azalma oldu? Eğitim sonunda hangi somut yararları sağladık? (Kirkpatrick, D. \& Kirkpatrick, J., 2006).

Eğitim programının hedeflerine baktığımızda tüm amacın bazı önemli sonuçlara ulaşmak olduğu görülür. Bunlar genellikle niteliğin, verimliliğin, kârın artması, daha iyi takım çalışması ve manevi gücün arttırılması gibi sonuçlardır. Eğitimciler bu istenen sonuçlara bakarak eğitimi alacak kişilerin bu sonuçlara ulaşabilmek için hangi davranışları göstermeleri gerektiğini belirler. Sonrasında eğitimciler, katılımcıların bu davranışları gösterebilmek için hangi bilgi, beceri ve tutumlara ihtiyaçları olduğunu saptar. Son olarak eğitim programının ihtiyaçlarını belirleyip bir program oluştururlar ve katılımcıların bu programı beğenmelerini, verilecek bilgi, beceri ve tutumları öğrenmelerini ve bunu işlerine yansıtabilmelerini umarlar (Kirkpatrick, D. \& Kirkpatrick, J., 2006).

Aşağıdaki yönergeler bu düzeyi gerçekleştirmede yardımcı olacaktır (Kirkpatrick; D., 1996);

1. Elverişli olacaksa bir kontrol grubu kullan.

2. Davranış değişikliği meydana gelmesi için yeterince zamanın geçmesini bekle.

3. Elverişli olacaksa eğitim öncesi ve sonrası davranış değişikliğini değerlendir.

4. Değerlendirmeyi uygun zamanlarda tekrarla.

5. Yarar maliyet dengesini koru.

6. Kanıt bulmak mümkün değilse eldeki delillerle tatmin ol.

Tepki ve öğrenme aşamaları eğitim programının içinde neler olduğuyla ilgilendiği için içsel kriterler olarak adlandırılmıştır. Davranış ve sonuç aşamaları ise eğitim programının dışında hatta sonrasında başladığı için dışsal kriterler olarak adlandırılırlar. Dışsal kriterlerin sadece öğrenmeden etkilenmediği, daha büyük organizasyonel ve ekonomik faktörlerden de etkilenebileceği göz ardı edilmemelidir (Praslova, 2010).

Eğitim programı ve eğitim programı geliştirme konusunda profesyonel olan pek çok kişi, Kirkpatrick modelinin 1. ve 2. aşamalarını rahatlıkla kullanmakta fakat 3.ve 4. düzeylerin kendi işleri olmadığı, bu düzeyleri gerçekleştirmenin maliyetli olduğu, zor olduğu, eğitimden sonra katılımcılara ulaşamamaları gibi nedenlerle bu düzeyleri kullanmaktan kaçınmaktadırlar. Fakat aslında 3. ve 4. düzeyleri gerçekleştirme hiçte sanıldığ 1 gibi zaman alıcı, zor ve maliyetli değildir (Kirkpatrick, D. \& Kirkpatrick, W. 2013).

Eğitim sonrasında toplanan bilgiler sonucunda eğitim programında değişiklik yapmak kadar önemli olan bir diğer nokta da paydaşların, katılımcıların ve yöneticilerin tüm süreçlerden haberdar edilmesidir. Paydaşlara en başta ilerleme raporlarını sunum olarak mı, yazılı mı, gösterge panoları şeklinde mi, brifing şeklinde mi vs. istedikleri sorulmalıdır (Kirkpatrick, D. \& Kirkpatrick, W. 2013).

Eğitim programı ve eğitim programı geliştirme uzmanları, işlerinin sadece eğitim aşamasında bittiğini düşünmekle yanılırlar. Etkili bir eğitimin sonuçlarının da etkili olması beklenir ve bu sorumluluk eğitim programı ve eğitim programı geliştirme uzmanlarındadır. Etkili bir eğitim sonrası uygulama ve değerlendirme planı için şunlara dikkat etmek gerekir (Kirkpatrick, D. \& Kirkpatrick, W. 2013).

1. Eğitime En Son Olması İstenen Şeyle Başla: Eğitim programını hazırlamaya başlamadan önce organizasyonun istediği en yüksek beklentiler göz önüne alınmalıdır.

INESJOURNAL

Uluslararası Eğitim Bilimleri Dergisi / The Journal of International Education Science Yll: 2, Sayı: 5, Aralık 2015, s. 89-97 
$\mathrm{Bu}$ bir anlamda 4. düzey sonuçların hedeflenmesidir. İkinci olarak 3. düzeyde gösterilmesi istenen davranışların doğru olarak belirlenmesi vardır. Bunun için istenen davranışların hangileri olduğu konusunda yeterli gözlem ve ölçümün yapılması gerekir. İnsanların nasıl davranmasının istendiği ve bu davranışların organizasyona nasıl katkıda bulunacağı belirlendikten sonra öğrenme hedefleri belirlenebilir ve eğitim programlanmaya başlanabilir.

2. Programın Tasarımı Aşamasında Eğitim Sonrası Uygulanacak Aktiviteleri Belirle: Eğitim sonrası yapılacakların eğitim programının yapım aşamasında belirlenmesi, kaynakların performans artışına sebep olma olasılığını arttıracaktır. Bunun için aşağıdakiler yardımcı olacaktır;

- Yöneticilerle, katılımcıların göstermesi istenen davranışların belirlenmesi konusunda fikir alışverişi yapılmalı, onların performans artışı konusundaki rolleri ve bunun için gerekli olacak araçlar ve yardım belirlenmelidir.

- Eğitimin katılımcılardan istenen kritik davranışları nasıl sergileyeceklerine dair öğrenme hedefleri tablo halinde yazılmalıdır.

- Eğitimin bir olay değil, devam eden bir süreç olduğu düşünülmeli ve eğitim sonrası faaliyetler de tasarlanmalidır.

3. Performans Beklentilerini Katılımcılara Açıkla.

4. Aktiviteleri Desteklemek İ̧̧in Teknolojiyi Kullan.

5. Bulguları Gözlemle ve Düzeltmeler Yap: Performans hakkında bilgi topladıkça gelecek eğitimlerin daha iyi olması açısından programda düzeltmeler yapılmalıdır. Değişiklikler gayet normaldir ve olması gereken de budur.

Sonuç olarak Kirkpatrick değerlendirme modeli dört aşamadan oluşan, aşamaları sırayla takip edilmesi gereken ve yurt dışında oldukça popüler olan bir modeldir. Kirkpatrick Dört Düzey Değerlendirme Modeli konusunda Türkçe literatürde kaynak eksikliği olduğu görülmektedir. Türkiye'de bu modelle ilgili az sayıda çalışmaya rastlanması, modelin Türkiye'de yeterince bilinmediğini akıllara getirmektedir. $\mathrm{Bu}$ durum iş eğitimlerine ve verilen eğitimlerin değerlendirilmesine yeterince önem verilmemesinden kaynaklanıyor olabilir. Bu çalışmanın gelecekte bu konuda yapılacak olan çalışmalara kaynak teşkil etmesi açısından literatüre katkıda bulunacağı düşünülmektedir.

\section{KAYNAKÇA}

Alliger, G.M., \& Janak, E.A. (1989). Kirkpatrick's Levels Of Training Criteria: Thirty Years Later. Personnel Psychology, 42, 331-342.

Altıntaş, L., \& Alimoğlu, M. K. (2013). Eğitim Becerilerini Geliştirmeye Yönelik Programların Üç Farklı Model İle Bir Arada Değerlendirilmesi: Logic-Bağlam-Girdi-Süreç-Ürün ve Kirkpatrick Modelleri. Tıp Ĕ̈itimi Dünyası, 36, 19-30.

Eroğlu, U. (2006). İşletmelerde Eğitim Faaliyetlerinin Etkinliğinin Ölçümüne İlişkin Bir Model Önerisi. Yönetim Bilimleri Dergisi, 4 (2), 111-132.

Hayes, A. (November, 2008). An interview with Donald Kirkpatrick: The father of evaluation. TrainingZone. http://www.trainingzone.co.uk/topic/training-cycle/interview-donaldkirkpatrick-father-evaluation. Erişim: 01.06.2014. 


\section{Kirkpatrick Dört Düzey Program Değerlendirme Modeli}

Kaufman, R., \& Keller, J. M. (1994). Levels of Evaluation:Beyond Kirkpatrick. Human Resource Development, 5(4), 371-380.

Kirkpatrick, D. (January, 1996). Great Ideas Revisited. Trainning \& Development, 50(1), 54-59.

Kirkpatrick, D. (2006). Seven Keys to Unlock the Four Levels of Evaluation. Performance Improvement , 45(7), 5-8.

Kirkpatrick, D., \& Kirkpatrick, J. (2006). Evaluating Training Programs: The Four Levels. California: Berrett-Koehler Publishers.

Kirkpatrick, J. (Agust, 2007). Hidden power of Kirkpatrick's Four Levels. Trainning \& Development, 61(8), 34-37.

Kirkpatrick, D., \& Kirkpatrick, J. (2007). Implementing the Four Levels. California: BerrettKoehler Publishers

Kirkpatrick, D., \& Kirkpatrick, W. (June, 2013). Creating a Post-Training Evaluation Plan. Trainning \& Development, 67(6), 26-28.

Praslova, L. (2010). Adaptation of Kirkpatrick’s Four Level Model Of Training

Criteria To Assessment Of Learning Outcomes And Program Evaluation İn Higher Education. Educ Asse Eval Acc, 22, 215-225. Doi: 10.1007/s11092-010-9098-7

Rajeev, P., Madan, M. S., \& Jayarajan, K. (2009). Revisiting Kirkpatrick's Model -An Evaluation Of An Academic Training Course. Current Science, 96(2), 272-276.

Uşun, S. (2012). Ĕgitimde Program Değerlendirme. Ankara: Anı Yayınc1lık.

Özaydın, B. , Günbatar, M. S. , Önal, N., \& Çakır, H. (2012). Öğretmen Yetiştirme Programlarının Sistemik Ve Sistematik Değerlendirilmesi. Eğitim Teknolojisi Kuram ve Uygulama. 2(1), 54-71 